\title{
Mini Review \\ Molecular mechanisms of glucose uptake in skeletal muscle at rest and in response to exercise
}

\author{
Rodrigo Martins Pereira \\ Universidade Estadual de Campinas, Limeira, SP, Brasil \\ Leandro Pereira de Moura \\ Universidade Estadual de Campinas, Campinas, SP, Brasil \\ Vitor Rosetto Muñoz \\ Universidade Estadual de Campinas, Limeira, SP, Brasil \\ Adelino Sanchez Ramos da Silva \\ Universidade de São Paulo, Ribeirão Preto, SP, Brasil \\ Rodrigo Stellzer Gaspar \\ Eduardo Rochete Ropelle \\ José Rodrigo Pauli \\ Universidade Estadual de Campinas, Limeira, SP, Brasil
}

\begin{abstract}
Glucose uptake is an important phenomenon for cell homeostasis and for organism health. Under resting conditions, skeletal muscle is dependent on insulin to promote glucose uptake. Insulin, after binding to its membrane receptor, triggers a cascade of intracellular reactions culminating in activation of the glucose transporter 4, GLUT4, among other outcomes. This transporter migrates to the plasma membrane and assists in glucose internalization. However, under special conditions such as physical exercise, alterations in the levels of intracellular molecules such as ATP and calcium act to regulate GLUT4 translocation and glucose uptake in skeletal muscle, regardless of insulin levels. Regular physical exercise, due to stimulating pathways related to glucose uptake, is an important non-pharmacological intervention for improving glycemic control in obese and diabetic patients. In this mini-review the main mechanisms involved in glucose uptake in skeletal muscle in response to muscle contraction will be investigated.
\end{abstract}

Keywords: exercise, skeletal muscle, glucose uptake, GLUT4

\section{Introduction}

The knowledge that exercise plays an important role in health is widely disseminated. In ancient Greece, the philosopher Hippocrates had mentioned in his works that both exercise and a healthy diet could promote health and prevent certain diseases. Nonetheless, the author did not imagine that several molecular changes might occur in response to exercise, culminating in many physiological responses, including the glucose uptake increment. With the advent of modern science and especially of molecular biology, the understanding of this process was significantly expanded. One pioneering study that confirmed glucose uptake with muscle contraction measured the arteriovenous difference in glucose derived from the masseter muscle in horses, demonstrating a reduction in the amount of glucose in this tissue after hay-chewing ${ }^{1}$.

Some decades later, Lawrence showed that physical exercise could enhance the effects of the hormone insulin, resulting in increased glucose consumption and internalization, suggesting that physical exercise could be relevant for the treatment of diabetic people ${ }^{2}$. Insulin injection prior to exercise resulted in greater reduction in blood glucose when compared to their peers who also exercised but did not receive the hormone. Following this evidence, it was shown that physical exercise increases the rate of glucose utilization in animals and humans ${ }^{3,5}$, even suggesting that its capture would occur in a similar manner to situations in which there was insulin stimulation. In a complementary way, it was also observed that the magnitude of the effect depends on the duration and intensity of the exercise ${ }^{6}$. Therefore, insulin and exercise have agonist actions in glucose uptake by skeletal muscle tissue process.

Further investigations have shown that a single exercise session can positively influence glucose uptake by muscle. It was shown that after 16 hours of a single swimming session - as this practice increases the expression of glucose transporter type 4 (GLUT4) by about $50 \%$ - there was an increase in glucose 
uptake in exercised muscles ${ }^{7}$. The justification lies in the fact that the transport of glucose stimulated by insulin or muscle contraction is increased in proportion to the increase of GLUT-4, as well as their translocation rate to the cell membrane ${ }^{8}$. This effect may remain for up to 48 hours after physical activity, suggesting the need of practice in a chronic manner to obtain its benefits continuously.

The identification of GLUT-4, abundantly expressed in adipose and muscle tissue, favored further studies about the mechanisms by which exercise can influence glucose uptake by skeletal muscle tissue ${ }^{9}$. Studies in animal models ${ }^{10,11}$ as well as in humans ${ }^{12-14}$ have shown that physical training increases the expression of GLUT-4, promoting glucose uptake in skeletal muscle.

Although the identification of the GLUT-4 has been very important, the following findings allowed to understand that exercise exerts actions on other molecules involved in glucose uptake. Glucose uptake utilizes insulin-dependent and insulin-independent cell signaling pathways. The latter category involves AMP-activated protein kinase (AMPK) and calcium/ calmodulin-dependent protein kinase $(\mathrm{CaMKK})^{15}$. The finding and understanding about the mechanisms of action of some proteins that act independently of insulin on glucose uptake allow to definitely recognize the benefits of using exercise as a non-pharmacological tool in the control of glucose homeostasis and in preventing and treating diabetes. Therefore, this minireview aims to describe the different mechanisms involved in glucose uptake at rest and in response to physical exercise.

\section{Glucose uptake mediated by insulin hormone}

Glucose uptake by insulin stimulation occurs after the hormone binds to its specific membrane receptor called insulin receptor (IR) ${ }^{16}$. The IR is a heterotetrameric protein with intrinsic tyrosine kinase activity. After this binding, the receptor undergoes a conformational alteration, triggering its autophosphorylation on tyrosine residues. Once activated, IR promotes the tyrosine phosphorylation of different substrates, including insulin receptor substrates 1 and 2 (IRS- 1 and IRS-2). The tyrosine phosphorylation of IRS-1 and IRS-2 allows them to associate and activate the phosphatidylinositol-3 kinase enzyme (PI3K). PI3K catalyzes the phosphorylation of membrane phosphoinositides at the position 3 of the inositol ring to produce phosphatidylinositol 3-phosphate, phosphatidylinositol 3,4-phosphate and phosphatidylinositol-3,4,5-phosphate. The latter product regulates the activity of phosphoinositide-dependent kinase-1 (PDK-1). Successively, PDK-1 phosphorylates protein kinase $\mathrm{B} / \mathrm{Akt}$ at serine/threonine kinase residue, which has a key role in insulin signaling pathway. When active, the Akt is responsible for the activation of AS160 (Akt substrate of $160 \mathrm{kDa})^{16}$. The AS160 can act in two significant ways on GLUT4 translocation to the periphery: 1) by reducing the "tethering" of the vesicle, by proteins called TUG, and thus releasing it to the periphery; 2) by increasing the activity of Rab proteins which will stimulate the translocation of these vesicles containing GLUT4 to the periphery. Therefore, these activation mechanisms and the release of vesicles containing GLUT4 are essential for glucose homeostasis at baseline. The increase of GLUT4 and its translocation to the sarcoplasm are extremely important for performance and health ${ }^{16}$.

Several studies have indicated that compromise at some point in this pathway can decrease glucose uptake, triggering important physiological changes that can lead to the development of various metabolic diseases, such as diabetes ${ }^{17}$. However, it is worth mentioning that there are alternative pathways in addition to insulin that are responsible for regulating glucose uptake, acting jointly in the regulation of glucose homeostasis. For example, studies using MIRKO animals (mice without insulin receptor in skeletal muscles - muscle insulin receptor knockout) show that there is reduced insulin signaling but no effect on the IGF-1 pathway (insulin-like growth factor, a growth factor similar to insulin), indicating that different pathways can act in a compensatory fashion to maintain signaling ${ }^{18}$. As there is homology between the molecules in the absence of insulin, IGF receptor receives the insulin signal and propagates intracellularly, partially compensating its absence. Thus, it is necessary to address some of the main mechanisms to promote glucose uptake, even in conditions of low levels of circulating insulin.

\section{Glucose uptake through physical exercise}

In skeletal muscle, glucose uptake depends on the presence of GLUT-4 on the cell membrane, so that it exerts its function of allowing the entry of glucose by facilitated diffusion. At baseline conditions, the great majority of GLUT4 molecules is stored in vesicles within the cell, keeping it in a quiescent, waiting for the recruitment signal. Therefore, under resting conditions, insulin is essential for glucose uptake in muscle tissue ${ }^{19}$. During exercise, there is an increase in blood flow to the active muscles, creating an incentive for the dilation of blood vessels responsible for irrigation of active muscles, thereby aiming to increase the surface area available for transport of glucose ${ }^{20}$. During muscle contraction, circulating insulin levels suffer no significant change, and in some cases even suffer a decrease. Thus, the muscle contractions and blood flow circulating levels of insulin act in synergism generating signals for translocation of GLUT4 to the membrane of the sarcolemma and t-tubules, thereby increasing glucose uptake by the cell ${ }^{21}$.

The amount of GLUT4 present in the sarcolemma and in the t-tubules is influenced by the efficiency of endocytosis and exocytosis processes of vesicles containing the protein in its inactive form. Insulin increases the amount of GLUT4 in muscle membrane primarily by increasing the stimulation of exocytosis ${ }^{22}$, while muscle contractions (that activate AMPK protein by depletion of ATP levels) not only increase the exocytosis rate but also decrease endocytosis rate of GLUT- $4^{23}$. This phenomenon may explain the additive effect of exercise on insulin in muscle glucose uptake ${ }^{24}$. The understanding that exercise cooperates in glucose uptake has led many researchers to investigate which mechanisms could be linked to muscle contraction and independently to the hormone insulin. 


\section{Cell signaling in skeletal muscle in response to physical exercise}

In general, physical exercise - and muscle contraction specifically - is able to activate a series of proteins that trigger the functional and/or structural protein alterations, ultimately promoting GLUT-4 translocation. Increases of both glucose uptake and metabolism in response to exercise are often associated with the effects of a single session of exercise in the levels of mRNA and in the absolute levels of GLUT-4 ${ }^{25}$. In addition to increased levels of GLUT-4, exercise is able to increase GLUT-4 translocation to myocellular membrane (related to increased exocytosis rate and lower endocytosis rate, as previously discussed), increasing the glucose uptake capacity in muscle cells ${ }^{19}$. The effects of exercise in increasing GLUT4 content and translocation involve some molecules that will be presented below.

\section{Physical exercise and glucose uptake mediated by AMPK}

A few years before the description of AMPK activation by physical exercise and related experimental evidence in humans, animal researches identified a drug compound known to act as a potent activator of this molecule, AICAR (5-aminoimidazole ribonucleotide-4-carboxamide). This compound, that mimics the intracellular increase in AMP, is capable of phosphorylating AMPK promoting glucose uptake and lipid oxidation in skeletal muscle ${ }^{26}$. Animal experiments also suggest that AMPK activation in skeletal muscle is capable of enhancing lipid oxidation and the glycogen resynthesis rate in response to exercise (having a protective effect on muscle glycogen stores) through the muscle contraction stimulus per se and through the increase of calcium release ${ }^{27}$.

Continuous and repetitive muscle contraction that is characteristic of exercise acts as a stressor agent. This activity causes depletion (momentary or extended) of ATP levels, which are rapidly resynthesized. However, at any given time, cellular ATP resynthesis becomes insufficient due to decreased levels of the enzyme creatine phosphate (CP) or even glucose, causing an increase in the ADP:ATP ratio and, consequently, in the AMP:ATP ratio. This phenomenon promotes the phosphorylation of LKB1 (liver kinase B1 - B1 liver kinase) which phosphorylates and activates AMPK, which can finally phosphorylate the AS160 protein $^{28,29}$. The AS160 can act in various ways to translate GLUT4-containing vesicles to the periphery. One is through the activation of Rab-GTP protein, which will trigger signal for the translocation of GLUT4 ${ }^{30}$. Another way is by reducing the TUG activity, protein "tethering" which binds to the vesicles, preventing its translocation ${ }^{31}$. Additionally, AMPK phosphorylates HDAC5 (histone deacetylase 5), which is exported from the nucleus promoting the activation of MEF2 (stimulating factor of myocyte 2) and GEF (stimulating factor GLUT4) as well as their combination. Both these transcription factors are related to the GLUT4 expression in skeletal muscle ${ }^{32}$. Thus, in addition to causing the translocation of GLUT4 molecules to the membrane, AMPK (in its active form) is also capable of regulating the expression of new GLUT-4 molecules.

\section{Muscle contractions and glucose uptake mediated by calcium ions}

Calcium ions have gained attention in recent decades due to their contribution to glucose uptake. Early studies found their participation in glucose homeostasis, when Sartorius muscle of frogs were incubated with caffeine ${ }^{33}$. Based on these results, it was observed that caffeine stimulates calcium release from the sarcoplasmic reticulum without plasma membrane depolarization and that this influx per se was sufficient to stimulate glucose uptake. Subsequently, studies with rat muscles incubated with caffeine or a chemical compound, which also stimulates calcium release in sufficient levels to promote muscle contraction ${ }^{34}$, also demonstrate the capacity of $\mathrm{Ca}^{2+}$ in increasing glucose uptake.

Furthermore, recent studies have brought new evidences of how $\mathrm{Ca}^{2+}$ promotes increased glucose uptake. It was observed that caffeine, through stimulation of $\mathrm{Ca}^{2+}$ ion pumps from the sarcoplasmic reticulum, increases cellular energy demand and ATP consumption. Since the increase in energy expenditure is responsible for the activation of AMPK, and it triggers processes that signal for the translocation of GLUT4 from intracellular vesicles to the plasma membrane, glucose uptake will be stimulated ${ }^{15}$. This phenomenon shows that $\mathrm{Ca}^{2+}$ influences the increase of glucose uptake, but with an indirect action, through AMPK activity.

Another hypothesis currently studied about the participation of $\mathrm{Ca}^{2+}$ in AMPK activation was observed in non-muscle tissues. It was observed the participation of calcium kinase-dependent protein/calmodulin (CaMKKs), highlighting the role of the CaMKK $\beta$ (which has the ability to phosphorylate AMPK in its active site $\left.\operatorname{Thr}^{172}\right)^{35}$. Therefore, it was created the hypothesis that $\mathrm{Ca}^{2+}$ directly activates AMPK in skeletal muscle via CaMKK, independent of increasing cellular energy consumption. Due to this, some studies were developed to examine this pathway in muscle tissue of rodents, but they showed controversial results ${ }^{15,36,37}$. Thus, it is not possible to state whether this action of $\mathrm{Ca}^{2+}$ in AMPK activation is direct or not. To date, the participation of $\mathrm{Ca}^{2+}$ in increasing glucose uptake in muscle is considered to be indirect, by increasing the cellular energy expenditure caused by the action of $\mathrm{Ca}^{2+}$ pumps present in the sarcoplasmic reticulum.

\section{Physical exercise, reactive oxygen species, and regulation of glucose uptake}

Some studies suggested the role of ROS in glucose uptake in response to muscle contraction, due to the fact that exercise increases significantly and transiently the production of ROS ${ }^{38,39}$. Some experiments that used donor ROS treatment in isolated skeletal muscle fibers observed that glucose uptake in the 
treated muscles was higher ${ }^{39}$. Other studies using non-specific inhibitors of ROS found divergent results, with no effect on glucose uptake in both rodents ${ }^{40}$ and humans ${ }^{41}$. Concerning these studies, it is suggested that the involvement of ROS in muscle glucose uptake would be restricted to conditions observed in vitro (intense electrical stimulation of isolated muscles fibers), without affecting the effects of exercise on the subjects. In a study with type 1 diabetics, administration of natural antioxidants (e.g., vitamin E) after exercise attenuated glucose uptake, indicating that reactive oxygen species act as regulators of glucose uptake and their inhibition might have a negative effect $\mathrm{t}^{42}$. These controversial results suggest the need for more studies to further elucidate this issue.

\section{Physical exercise, nitric oxide synthesis, and glucose uptake}

Nitric oxide (NO) is synthesized by three isoforms of nitric oxide synthase: iNOS (inducible nitric oxide synthase), eNOS (endothelial nitric oxide synthase), and nNOS (neuronal nitric oxide synthase). The role of NO is commonly related to vasodilation of the endothelium to facilitate the coming of nutrients distribution to the active muscles as well as the removal and transport of metabolites, maintaining cellular homeostasis ${ }^{43,44}$. Studies using animals showed that 4 and 8 weeks of treadmill running training ${ }^{47,48}$ as 4 weeks of swimming training ${ }^{49}$ can upregulate nNOS levels in the skeletal muscle of trained mice. On the other hand, studies with humans are not clear in showing if there is an increase in the levels of nNOS and NO in skeletal muscle in response to exercise $e^{45,46}$.

Infusion of L-NAME (a known pharmacological inhibitor of NOS) in the femoral artery of humans during exercise on a cycle ergometer, performed at $60 \%$ of $\mathrm{VO}_{2}$ peak (moderate intensity), substantially attenuates glucose uptake in healthy subjects and in patients with type 2 diabetes, with no changes in blood flow in the lower limbs, blood pressure or insulin and glucose concentrations ${ }^{51,52}$, indicating that there must be an effect of NOS on muscle contraction-induced glucose uptake.

These results indicate that the inhibition of molecules that produce NO attenuates glucose uptake in skeletal muscle during muscle contraction, without affecting the flow of glucose into muscle. It is suggested that the release of NO by muscular stimulation occurs only in high-intensity exercises. In humans, the inhibition of NOS in low-intensity exercise did not affect glucose uptake, with significant alterations for moderate intensities $^{53}$. In animal models, the treatment with NO donor enhances glucose uptake in the EDL muscle of $\mathrm{C} 57 \mathrm{BL} / 6 \mathrm{~J}$ mice and this effect was ceased by the use of the NO inhibitor ${ }^{54}$.

On the other hand, excessive concentrations of NO can induce insulin resistance in skeletal muscle by binding of NO to specific cysteine residues present in IR $\beta$ proteins, IRS-1 and Akt, reducing the ability to activate these molecules when stimulated by insulin ${ }^{55}$. The modification of protein activity mediated by the binding of NO to cysteine residues is known as S-nitrosation or S-nitrosylation and it is becoming a key mechanism in the insulin resistance process ${ }^{56}$.

Specifically, aberrant production of NO in mammals appears to be mediated by the inducible isoform, iNOS, which is highly expressed in certain situations such as oxidative stress and inflammation. In light of these findings, it was demonstrated that iNOS knockout mice are protected from developing insulin resistance induced by obesity ${ }^{57}$ and aging ${ }^{58}$. Interestingly, it was observed that acute aerobic exercise can reduce the protein content of iNOS, S-nitrosation of IR $\beta$, IRS-1 and Akt and, thus, decrease insulin resistance in the skeletal muscle of obese rats ${ }^{59}$.

In summary, it was shown that at physiological levels NO is required for increasing glucose uptake by skeletal muscle during exercise. This suggests a relationship between NO and AS160 protein; however, the underlying molecular mechanisms remain to be elucidated. Studies have also shown that exaggerated NO production can reduce glucose uptake after insulin stimulation.

\section{Muscle temperature and glucose uptake}

Recently, the increased temperature of skeletal muscle was considered as a potential inductor for increased glucose uptake. An elegant study demonstrated in animal models that the simple increase of skeletal muscle temperature is able to stimulate glucose uptake through the activations of AMPK and Akt, which were partially reversed after the use of pharmacological inhibitors of these proteins, such as compound $\mathrm{C}$ and Wortmannin, respectively ${ }^{60}$.

Other studies also suggested that the increased glucose uptake, which occurs because of increase in muscle temperature, is due to the increased production of reactive oxygen species (ROS) that regulates the activity of NOS (promoting NO production) favoring the formation of RNS (as a result of the reaction of NO with ROS previously exposed). ROS and RNS provoke a stimulus for the translocation of GLUT4 to the muscle cell membrane in a way not fully understood to date ${ }^{61,62}$. However, it is worth highlighting that the results of increased glucose uptake in response to increased skeletal muscle temperature are transient. Further studies about the mechanisms through which the muscle temperature interferes with this process, the transition of these findings to studies with humans, and the use of this knowledge in practice should be developed. This may bring new insights about the thermal baths (soaking in hot water), preheating at the beginning of physical activity interventions with equipment that causes local heating, etc.

\section{Actin cytoskeleton and glucose uptake}

Several articles have addressed the role of the reorganization of the actin cytoskeleton - which occurs during the shortening/ relaxation of the muscle fiber - in glucose uptake. This momentary reorganization would not only be capable of modulating intracellular traffic of GLUT-4, but also the signaling that occurs prior to its translocation into the muscle cell membrane, acting in synergy with other signaling molecules, enhancing GLUT-4 
action. This hypothesis was confirmed by experiments using skeletal muscle myotubes and rodents, which demonstrated that insulin signaling (specifically the GLUT-4 translocation signal) depends on transient changes in the actin cytoskeleton ${ }^{63,64}$. Confirming these results, experiments using drugs that are able to break the actin filaments showed that under these conditions, both in cells and in skeletal muscle of rodents, the translocation of GLUT-4 and subsequent glucose uptake by the cell after stimulation with insulin was impaired ${ }^{65}$. More thoroughly, these results are related to the functioning of a specific protein, Rac1. This protein is a GTPase responsible for mediating the stimulatory effect on exocytosis rates of GLUT-4, resulting in release of intracellular vesicles and their subsequent translocation to the membrane myocyte ${ }^{64}$. It was demonstrated, both in rodents and in humans, through the increase in GTP levels, that exercise increases the activation of Rac1. Nevertheless, it was observed that the pharmacological inhibition or genetic ablation of Rac1 impaired the increased glucose uptake obtained as a result of physical exercise ${ }^{66}$. Subsequently, the same group of researchers showed that the signaling of Rac1 would be downregulated in skeletal muscles of rodents that are insulin-resistant ${ }^{67}$.

Another protein located in the cytoskeleton is Myolc, which is also related to motor activity. It was suggested that this protein can act as a contributor to glucose uptake induced by muscle contraction. An elegant study promoted the mutated expression of this protein in skeletal muscles of mice and demonstrated that Myolc is involved in the translocation of GLUT4, since the animals with mutated Myo1c had glucose uptake attenuated in response to muscle contraction stimulus. These observations indicate that these proteins and possibly others, which are related to cytoskeletal composition, regulate the effect of exercise in increasing glucose uptake in exercised muscles. Accordingly, these proteins can be targeted for future studies on insulin resistance treatment, as well as studies to provide a better understanding of this complex phenomenon ${ }^{68}$.

\section{Conclusion}

In this mini-review we addressed the most recent findings with regard to glucose uptake mechanisms in skeletal muscle in response to exercise. Several studies indicate that exercise can promote robust control of glucose homeostasis through various cellular mechanisms. Figure 1 shows a schematic summary of the molecular mechanisms regulated by physical exercise that are related to increased glucose uptake in skeletal muscle. We presented information showing that exercise is capable of regulating insulin-dependent and non-insulin-dependent molecular pathways to increase glucose uptake in exercised skeletal muscle.

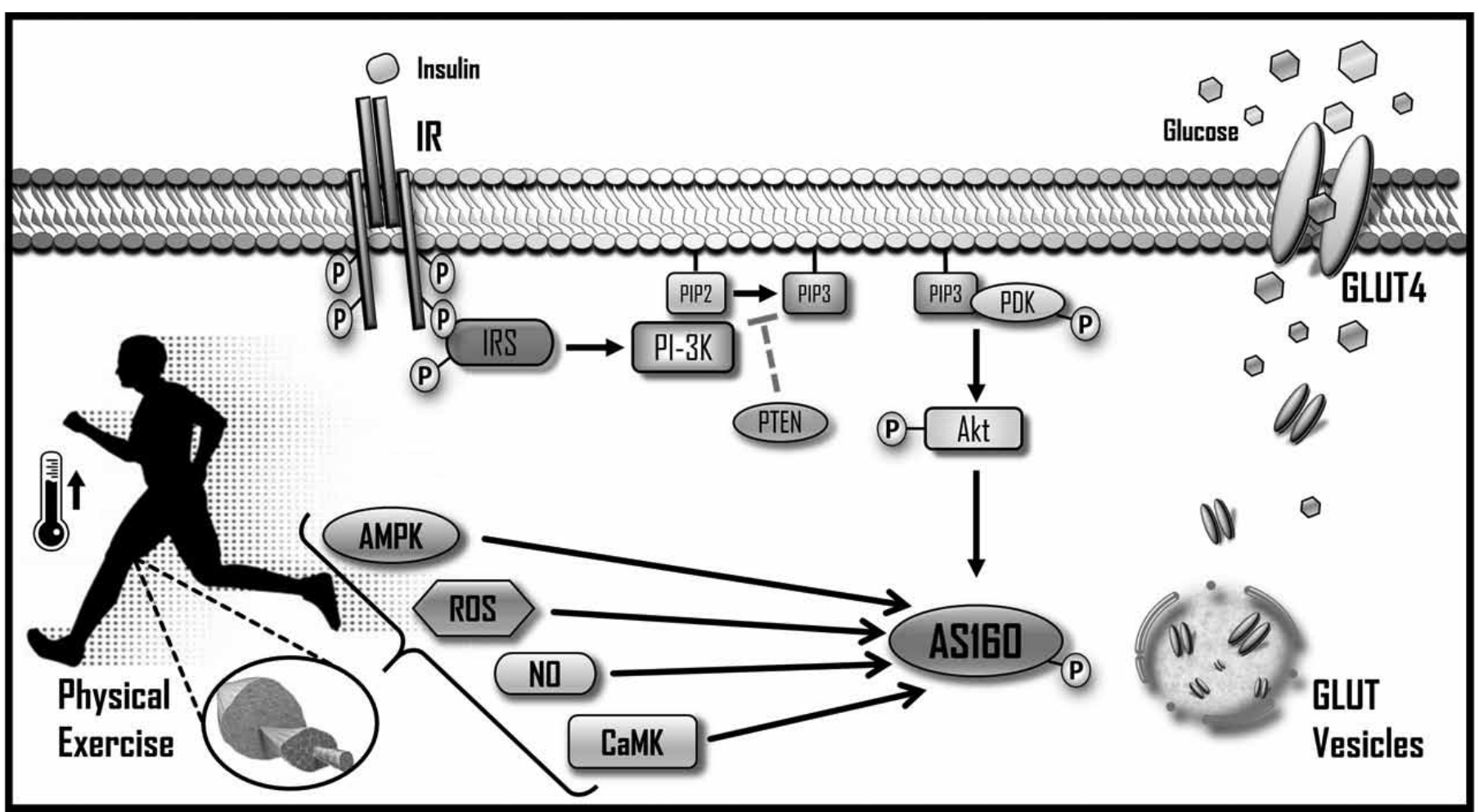

Figure 1. Molecular mechanisms involved in skeletal muscle glucose uptake at rest and in response to exercise. IR, Insulin receptor; IRS, insulin receptor substrate; PI-3K, phosphatidylinositol 3-kinase; PIP2, phosphatidylinositol 4,5-bisphosphate; PIP3, phosphatidylinositol (3,4,5)-trisphosphate; PDK, phosphoinositide-dependent kinase; Akt, protein kinase B; AS160, Akt substrate of $160 \mathrm{kDa}$; GLUT, glucose transporter; AMPK, AMP-activated protein kinase; ROS, reactive oxygen species; NO, nitric oxide; $\mathrm{CaMK}, \mathrm{Ca} 2+/$ calmodulin-dependent protein kinase. 


\section{References}

1. Chauveau MA, Kaufmann M. Experiences pour la determination du coefficient de l'activite nutritive et respiratoire des muscles en repos et en travail. C R Acad Sci. 1887;104:1126-32.

2. Lawrence RD. The Effect of Exercise on Insulin Action in Diabetes. Br Med J. 1926;1(3406):648-50.

3. Christophe J, Mayer J. Effect of exercise on glucose uptake in rats and men. J Appl Physiol. 1958;13(2):269-72.

4. Goldstein MS, Mullick V, Huddlestun B, Levine R. Action of muscular work on transfer of sugars across cell barriers; comparison with action of insulin. Am J Physiol. 1953;173(2):212-6.

5. Jorfeldt L, Wahren J. Human forearm muscle metabolism during exercise. VI. Substrate utilization in prolonged fasting. Scand J Clin Lab Invest. 1970;26:73-81.

6. Coyle EF, Hagberg JM, Hurley BF, Martin WH, Ehsani AA, Holloszy JO. Carbohydrate feeding during prolonged strenuous exercise can delay fatigue. J Appl Physiol. 1983;55(1 Pt 1):230-5.

7. Ren JM, Semenkovich CF, Gulve EA, Gao J, Holloszy JO. Exercise induces rapid increases in GLUT4 expression, glucose transport capacity, and insulin-stimulated glycogen storage in muscle. J Biol Chem. 1994;269(20):14396-401.

8. Host HH, Hansen PA, Nolte LA, Chen MM, Holloszy JO. Rapid reversal of adaptive increases in muscle GLUT-4 and glucose transport capacity after training cessation. J Appl Physiol. 1998;84(3):798-802.

9. Charron MJ, Brosius FC, Alper SL, Lodish HF. A glucose transport protein expressed predominately in insulin-responsive tissues. Proc Natl Acad Sci U S A. 1989;86(8):2535-9.

10. Luciano E, Carneiro EM, Carvalho CRO, Carvalheira JBC, Peres $\mathrm{SB}$, Reis MAB, et al. Endurance training improves responsiveness to insulin and modulates insulin signal transduction through the phosphatidylinositol 3-kinase/Akt-1 pathway. Eur J Endocrinol. 2002;147(1):149-57.

11. Pauli JR, Ropelle ER, Cintra DE, Souza CT de. Effects of Physical Exercise in the Ampka Expression and Activity in High-fat Diet Induced Obese Rats. Rev Bras Med do Esporte. 2009;15(2):98-103.

12. Christ-Roberts CY, Pratipanawatr T, Pratipanawatr W, Berria R, Belfort R, Kashyap S, et al. Exercise training increases glycogen synthase activity and GLUT4 expression but not insulin signaling in overweight nondiabetic and type 2 diabetic subjects. Metabolism. 2004;53(9):1233-42.

13. O'Gorman DJ, Karlsson HKR, McQuaid S, YousifO, Rahman Y, Gasparro D, et al. Exercise training increases insulin-stimulated glucose disposal and GLUT4 (SLC2A4) protein content in patients with type 2 diabetes. Diabetologia. 2006;49(12):2983-92.

14. Frøsig C, Rose AJ, Treebak JT, Kiens B, Richter EA, Wojtaszewski JFP. Effects of endurance exercise training on insulin signaling in human skeletal muscle: interactions at the level of phosphatidylinositol 3-kinase, Akt, and AS160. Diabetes. 2007;56(8):2093-102.

15. Witczak CA, Fujii N, Hirshman MF, Goodyear LJ. Ca2+/ calmodulin-dependent protein kinase kinase-alpha regulates skeletal muscle glucose uptake independent of AMP-activated protein kinase and Akt activation. Diabetes. 2007;56(5):1403-9.
16. Leney SE, Tavaré JM. The molecular basis of insulin-stimulated glucose uptake: signalling, trafficking and potential drug targets. J Endocrinol. 2009;203(1):1-18.

17. Hotamisligil GS. Inflammation and metabolic disorders 1. Nature. 2006;444(1476-4687):860-7.

18. He Z, Opland DM, Way KJ, Ueki K, Bodyak N, Kang PM, et al. Regulation of vascular endothelial growth factor expression and vascularization in the myocardium by insulin receptor and PI3K/ Akt pathways in insulin resistance and ischemia. Arterioscler Thromb Vasc Biol. 2006;26(4):787-93.

19. Bradley H, Shaw CS, Bendtsen C, Worthington PL, Wilson OJ, Strauss JA, et al. Visualization and quantitation of GLUT4 translocation in human skeletal muscle following glucose ingestion and exercise. Physiol Rep. 2015;3(5):e12375.

20. Andersen P, Saltin B. Maximal perfusion of skeletal muscle in man. J Physiol. 1985;366:233-49.

21. Richter EA, Hargreaves M. Exercise, GLUT4, and Skeletal Muscle Glucose Uptake. Physiol Rev. 2013;93(3):993-1017.

22. Stöckli J, Fazakerley DJ, James DE. GLUT4 exocytosis. J Cell Sci. 2011;124(Pt 24):4147-59.

23. Huang S, Czech MP. The GLUT4 glucose transporter. Cell Metab. 2007;5(4):237-52.

24. Ploug T, Galbo H, Vinten J, Jørgensen M, Richter EA. Kinetics of glucose transport in rat muscle: effects of insulin and contractions. Am J Physiol. 1987;253(1 Pt 1):E12-20.

25. Kraniou Y, Cameron-Smith D, Misso M, Collier G, Hargreaves M. Effects of exercise on GLUT-4 and glycogenin gene expression in human skeletal muscle. J Appl Physiol. 2000;88(2):794-6.

26. Merrill GF, Kurth EJ, Hardie DG, Winder WW. AICA riboside increases AMP-activated protein kinase, fatty acid oxidation, and glucose uptake in rat muscle. Am J Physiol. 1997;273(6 Pt 1):E1107-12.

27. Jeon SM. Regulation and function of AMPK in physiology and diseases. Exp Mol Med. Nature Publishing Group; 2016;48(7):e245.

28. Stanford KI, Goodyear LJ. Exercise and type 2 diabetes: molecular mechanisms regulating glucose uptake in skeletal muscle. Adv Physiol Educ. 2014;38(4):308-14.

29. Treebak JT, Glund S, Deshmukh A, Klein DK, Long YC, Jensen TE, et al. AMPK-mediated AS160 phosphorylation in skeletal muscle is dependent on AMPK catalytic and regulatory subunits. Diabetes. 2006;55(7):2051-8.

30. Cartee GD. Mechanisms for greater insulin-stimulated glucose uptake in normal and insulin-resistant skeletal muscle after acute exercise. American Physiological Society Am J Physiol Endocrinol Metab; 201;309(12):E949-59.

31. Bogan JS, Hendon N, McKee AE, Tsao TS, Lodish HF. Functional cloning of TUG as a regulator of GLUT4 glucose transporter trafficking. Nature. 2003;425(6959):727-33.

32. McGee SL, Sparling D, Olson AL, Hargreaves M. Exercise increases MEF2- and GEF DNA-binding activity in human skeletal muscle. FASEB J. 2006;20(2):348-9.

33. Holloszy JO, Narahara HT. Enhanced permeability to sugar associated with muscle contraction. Studies of the role of $\mathrm{Ca}++. \mathrm{J}$ Gen Physiol. 1967;50(3):551-62. 
34. Holloszy JO, Narahara HT. Nitrate Ions: Potentiation of Increased Permeability to Sugar Associated with Muscle Contraction. Science. 1967 Feb 3;155(3762):573-5.

35. Hawley SA, Pan DA, Mustard KJ, Ross L, Bain J, Edelman $\mathrm{AM}$, et al. Calmodulin-dependent protein kinase kinase- $\beta$ is an alternative upstream kinase for AMP-activated protein kinase. Cell Metab. 2005;2(1):9-19.

36. Youn JH, Gulve EA, Holloszy JO. Calcium stimulates glucose transport in skeletal muscle by a pathway independent of contraction. Am J Physiol. 1991;260(3 Pt 1):C555-61.

37. Mul JD, Stanford KI, Hirshman MF, Goodyear LJ. Exercise and Regulation of Carbohydrate Metabolism. Prog Mol Biol Transl Sci. 2015; 135:17-37.

38. Reid MB. Free radicals and muscle fatigue: Of ROS, canaries, and the IOC. Free Radic Biol Med. 2008;44(2):169-79.

39. Jensen TE, Schjerling P, Viollet B, Wojtaszewski JFP, Richter EA. AMPK alphal activation is required for stimulation of glucose uptake by twitch contraction, but not by $\mathrm{H} 2 \mathrm{O} 2$, in mouse skeletal muscle. PLoS One. 2008;3(5):e2102.

40. Merry TL, Dywer RM, Bradley EA, Rattigan S, McConell GK. Local hindlimb antioxidant infusion does not affect muscle glucose uptake during in situ contractions in rat. J Appl Physiol. 2010;108(5):1275-83.

41. Merry TL, Wadley GD, Stathis CG, Garnham AP, Rattigan S, Hargreaves M, et al. N-Acetylcysteine infusion does not affect glucose disposal during prolonged moderate-intensity exercise in humans. J Physiol. 2010;588(Pt 9):1623-34.

42. Merry TL, McConell GK. Do Reactive Oxygen Species Regulate Skeletal Muscle Glucose Uptake During Contraction? Exerc Sport Sci Rev. 2012;40(2):102-5.

43. Andrade FH, Reid MB, Allen DG, Westerblad H. Effect of nitric oxide on single skeletal muscle fibres from the mouse. J Physiol. 1998;509(2):577-86.

44. Reid MB. Role of nitric oxide in skeletal muscle: synthesis, distribution and functional importance. Acta Physiol Scand. 1998;162(3):401-9.

45. Bradley SJ, Kingwell BA, Canny BJ, McConell GK. Skeletal muscle neuronal nitric oxide synthase micro protein is reduced in people with impaired glucose homeostasis and is not normalized by exercise training. Metabolism. 2007;56(10):1405-11.

46. Frandsen U, Höffner L, Betak A, Saltin B, Bangsbo J, Hellsten Y. Endurance training does not alter the level of neuronal nitric oxide synthase in human skeletal muscle. J Appl Physiol. 2000;89(3):1033-8.

47. Balon TW, Nadler JL. Evidence that nitric oxide increases glucose transport in skeletal muscle. J Appl Physiol. 1997;82(1):359-63. Available from: http://jap.physiology.org/content/82/1/359. abstract

48. Vassilakopoulos T, Deckman G, Kebbewar M, Rallis G, Harfouche $\mathrm{R}$, Hussain SNA. Regulation of nitric oxide production in limb and ventilatory muscles during chronic exercise training. Am J Physiol - Lung Cell Mol Physiol. 2003 Mar 1;284(3):L452-7.

49. Tatchum-Talom R, Schulz R, McNeill JR, Khadour FH. Upregulation of neuronal nitric oxide synthase in skeletal muscle by swim training. Am J Physiol Heart Circ Physiol. 2000;279(4):H1757-66.

50. Adams L, Franco MC, Estevez AG. Reactive nitrogen species in cellular signaling. Exp Biol Med. 2015 Jun 1;240(6):711-7.

51. Kingwell BA, Formosa M, Muhlmann M, Bradley SJ, McConell GK. Nitric oxide synthase inhibition reduces glucose uptake during exercise in individuals with type 2 diabetes more than in control subjects. Diabetes. 2002;51(8):2572-80.

52. Bradley SJ, Kingwell BA, McConell GK. Nitric oxide synthase inhibition reduces leg glucose uptake but not blood flow during dynamic exercise in humans. Diabetes. 1999;48(9):1815-21.

53. Ilkka H, Bengt $\mathrm{S}$, Jukka K, Sipilä HT, Vesa O, Pirjo N, et al. Skeletal muscle blood flow and oxygen uptake at rest and during exercise in humans: a pet study with nitric oxide and cyclooxygenase inhibition. Am J Physiol Heart Circ Physiol. 2011;300(4):H1510-7.

54. Merry TL, Lynch GS, McConell GK. Downstream mechanisms of nitric oxide-mediated skeletal muscle glucose uptake during contraction. Am J Physiol Regul Integr Comp Physiol. 2010;299(6):R1656-65.

55. Carvalho-Filho MA, Ueno M, Hirabara SM, Seabra AB, Carvalheira JBC, de Oliveira MG, et al. S-nitrosation of the insulin receptor, insulin receptor substrate 1 , and protein kinase B/Akt: a novel mechanism of insulin resistance. Diabetes. 2005;54(4):959-67.

56. Yasukawa T, Tokunaga E, Ota H, Sugita H, Martyn JAJ, Kaneki M. S-Nitrosylation-dependent Inactivation of Akt/Protein Kinase B in Insulin Resistance. J Biol Chem. 2005 Mar 4;280(9):7511-8.

57. Perreault M, Marette A. Targeted disruption of inducible nitric oxide synthase protects against obesity-linked insulin resistance in muscle. Nat Med. 2001 Oct 1;7(10):1138-43.

58. Ropelle ER, Pauli JR, Cintra DE, Da Silva AS, De Souza CT, Guadagnini D, et al. Targeted disruption of inducible nitric oxide synthase protects against aging, S-nitrosation, and insulin resistance in muscle of male mice. Diabetes. 2013;62(2):466-70.

59. Pauli JR, Ropelle ER, Cintra DE, Carvalho-Filho MA, Moraes JC, De Souza CT, et al. Acute physical exercise reverses S-nitrosation of the insulin receptor, insulin receptor substrate 1 and protein kinase B/Akt in diet-induced obese Wistar rats. J Physiol. 2008;586(2):659-71.

60. Koshinaka K, Kawamoto E, Abe N, Toshinai K, Nakazato M, Kawanaka K. Elevation of muscle temperature stimulates muscle glucose uptake in vivo and in vitro. J Physiol Sci. 2013;63(6):409-18.

61. Venturini G, Colasanti M, Fioravanti E, Bianchini A, Ascenzi P. Direct effect of temperature on the catalytic activity of nitric oxide synthases types I, II, and III. Nitric Oxide. 1999;3(5):375-82.

62. Murrant CL, Reid MB. Detection of reactive oxygen and reactive nitrogen species in skeletal muscle. Microsc Res Tech. 2001;55(4):236-48.

63. Khayat ZA, Tong P, Yaworsky K, Bloch RJ, Klip A. Insulininduced actin filament remodeling colocalizes actin with phosphatidylinositol 3-kinase and GLUT4 in L6 myotubes. J Cell Sci. 2000;113 Pt 2:279-90. 
64. Ueda S, Kitazawa S, Ishida K, Nishikawa Y, Matsui M, Matsumoto $\mathrm{H}$, et al. Crucial role of the small GTPase Racl in insulin-stimulated translocation of glucose transporter 4 to the mouse skeletal muscle sarcolemma. FASEB J. 2010;24(7):2254-61.

65. Török D, Patel N, Jebailey L, Thong FSL, Randhawa VK, Klip A, et al. Insulin but not PDGF relies on actin remodeling and on VAMP2 for GLUT4 translocation in myoblasts. J Cell Sci. 2004;117(Pt 22):5447-55.

66. Sylow L, Jensen TE, Kleinert M, Mouatt JR, Maarbjerg SJ, Jeppesen $\mathrm{J}$, et al. Rac1 is a novel regulator of contractionstimulated glucose uptake in skeletal muscle. Diabetes. 2013;62(4):1139-51.

67. Sylow L, Jensen TE, Kleinert M, Højlund K, Kiens B, Wojtaszewski J, et al. Rac1 signaling is required for insulin-stimulated glucose uptake and is dysregulated in insulin-resistant murine and human skeletal muscle. Diabetes. 2013;62(6):1865-75.

68. Toyoda T, An D, Witczak CA, Koh HJ, Hirshman MF, Fujii N, et al. Myolc regulates glucose uptake in mouse skeletal muscle. J Biol Chem. 2011; 286(6):4133-40.

\section{Acknowledgments}

The authors thank FAPESP, for its indispensable support.

\section{Corresponding author}

\author{
José Rodrigo Pauli \\ Universidade Estadual de Campinas, Limeira, SP, Brasil
} Email:jose.pauli@fca.unicamp.br

Manuscript received on August 26, 2016

Manuscript accepted on September 26, 2016

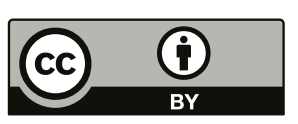

Motriz. The Journal of Physical Education. UNESP. Rio Claro, SP, Brazil - eISSN: 1980-6574 - under a license Creative Commons - Version 3.0 